\title{
Biofabrication: reappraising the definition of an evolving field
}

Citation for published version (APA):

Groll, J., Boland, T., Blunk, T., Burdick, J. A., Cho, D-W., Dalton, P. D., Derby, B., Forgacs, G., Li, Q., Mironov, V. A., Moroni, L., Nakamura, M., Shu, W., Takeuchi, S., Vozzi, G., Woodfield, T. B. F., Xu, T., Yoo, J. J., \& Malda, J. (2016). Biofabrication: reappraising the definition of an evolving field. Biofabrication, 8(1), [013001]. https://doi.org/10.1088/1758-5090/8/1/013001

Document status and date:

Published: 01/03/2016

DOI:

10.1088/1758-5090/8/1/013001

Document Version:

Publisher's PDF, also known as Version of record

Document license:

Taverne

Please check the document version of this publication:

- A submitted manuscript is the version of the article upon submission and before peer-review. There can be important differences between the submitted version and the official published version of record.

People interested in the research are advised to contact the author for the final version of the publication, or visit the DOI to the publisher's website.

- The final author version and the galley proof are versions of the publication after peer review.

- The final published version features the final layout of the paper including the volume, issue and page numbers.

Link to publication

\footnotetext{
General rights rights.

- You may freely distribute the URL identifying the publication in the public portal. please follow below link for the End User Agreement:

www.umlib.nl/taverne-license

Take down policy

If you believe that this document breaches copyright please contact us at:

repository@maastrichtuniversity.nl

providing details and we will investigate your claim.
}

Copyright and moral rights for the publications made accessible in the public portal are retained by the authors and/or other copyright owners and it is a condition of accessing publications that users recognise and abide by the legal requirements associated with these

- Users may download and print one copy of any publication from the public portal for the purpose of private study or research.

- You may not further distribute the material or use it for any profit-making activity or commercial gain

If the publication is distributed under the terms of Article $25 \mathrm{fa}$ of the Dutch Copyright Act, indicated by the "Taverne" license above, 
PERSPECTIVE

\section{Biofabrication: reappraising the definition of an evolving field}

To cite this article: Jürgen Groll et al 2016 Biofabrication 8013001

View the article online for updates and enhancements.

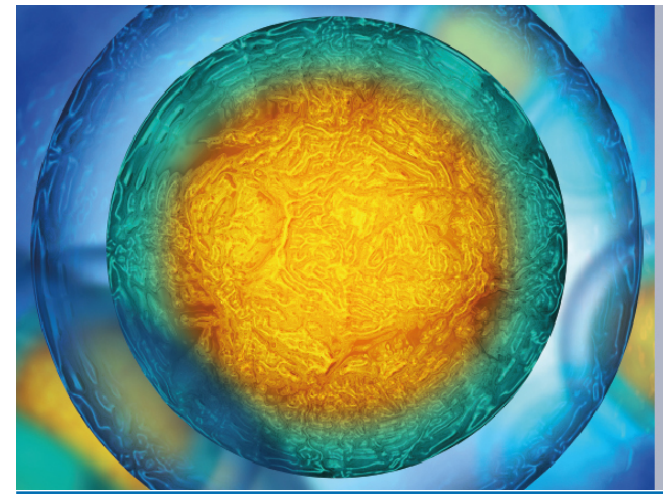

Biophysical Society $\quad$ IOP $\mid$ ebooks

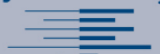

Your publishing choice in all areas of biophysics

research.

Start exploring the collection-download the first chapter of every title for free.

\section{Related content}

- Bioprinting is coming of age: report from
$\frac{\text { the International Conference on }}{\text { Bioprinting and Biofabrication in Bordeaux }}$
$\frac{\left(3 B^{\prime} 09\right)}{\text { Fabien Guillemot, Vladimir Mironov and }}$
Makoto Nakamura
- Biofabrication: a 21st century
manufacturing paradigm
V Mironov, T Trusk, V Kasyanov et al.
- Converging biofabrication and organoid
technologies: the next frontier in hepatic
and intestinal tissue engineering?
Kerstin Schneeberger, Bart Spee, Pedro
Costa et al.

\section{Recent citations}

$$
\begin{aligned}
& \text { Current progress, challenges, and future } \\
& \text { prospects of testis organoidst } \\
& \text { Tat-Chuan Cham et al } \\
& \frac{\text { Extracellular matrix (ECM)-derived bioinks }}{\text { designed to foster vasculogenesis and }} \\
& \frac{\text { neurite outgrowth: Characterization and }}{\text { bioprinting }} \\
& \text { Hugo Oliveira et al } \\
& \text { In-Vitro Cytotoxicity Study: Cell Viability } \\
& \text { and Cell Morphology of Carbon } \\
& \text { Nanofibrous Scaffold/Hydroxyapatite } \\
& \text { Nanocomposites } \\
& \text { Asmaa M. Abd El-Aziz et al }
\end{aligned}
$$




\title{
Biofabrication
}

\section{PERSPECTIVE}

CrossMark

\section{Biofabrication: reappraising the definition of an evolving field}

PUBLISHED

8 January 2016

Jürgen Groll ${ }^{1}$, Thomas Boland ${ }^{2}$, Torsten Blunk ${ }^{3}$, Jason A Burdick ${ }^{4}$, Dong-Woo Cho ${ }^{5}$, Paul D Dalton ${ }^{1}$, Brian Derby $^{6}$, Gabor Forgacs ${ }^{7,8}$, Qing Li ${ }^{9}$, Vladimir A Mironov ${ }^{10}$, Lorenzo Moroni ${ }^{11}$, Makoto Nakamura ${ }^{12}$, Wenmiao Shu $^{13}$, Shoji Takeuchi ${ }^{14}$, Giovanni Vozzi ${ }^{15}$, Tim B F Woodfield ${ }^{16}$, Tao Xu ${ }^{17}$, James J Yoo ${ }^{18}$ and Jos Malda ${ }^{19,20}$

1 Department of Functional Materials in Medicine and Dentistry, University of Würzburg, Würzburg, Germany

2 Department of Metallurgical, Materials and Biomedical Engineering, The University of Texas, El Paso, TX, USA

3 Department of Trauma, Hand, Plastic and Reconstructive Surgery, University Hospital Würzburg, Würzburg, Germany

4 Department of Bioengineering, University of Pennsylvania, Philadelphia, PA, USA

Department of Mechanical Engineering, Pohang University of Science and Technology, Pohang, Korea

6 School of Materials, University of Manchester, Manchester, M13 9PL, UK

Department of Physics, Biology and Biomedical Engineering, University of Missouri, Columbia, MO, USA

8 Modern Meadow Inc., Brooklyn, NY, USA

9 School of Aerospace, Mechanical and Mechatronic Engineering, The University of Sydney, Sydney, Australia

10 3D Bioprinting Solutions, Moscow, Russian Federation

11 MERLN Institute for Technology-Inspired Regenerative Medicine, Department of Complex Tissue Regeneration, Maastricht University, Maastricht, The Netherlands

12 Graduate School of Science and Engineering for Research, University of Toyama, Toyama, Japan

13 School of Engineering and Physical Sciences, Heriot-Watt University, Edinburgh, UK

14 Institute of Industrial Science, University of Tokyo, Tokyo, Japan

15 Research Center 'E. Piaggio' \& Dipartimento di Ingegneria dell'Informazione, University of Pisa, Pisa, Italy

16 Department of Orthopedic Surgery and Centre for Bioengineering \& Nanomedicine, University of Otago, Christchurch, New Zealand

17 Department of Mechanical Engineering, Tsinghua University, Beijing, People's Republic of China

18 Wake Forest Institute for Regenerative Medicine, Wake Forest School of Medicine, Winston-Salem, NC, USA

19 Department of Orthopedics, University Medical Center Utrecht, Utrecht, The Netherlands

20 Department of Equine Sciences, Faculty of Veterinary Medicine, Utrecht University, Utrecht, The Netherlands

E-mail: juergen.groll@fmz.uni-wuerzburg.de

Keywords: Biofabrication, Bioprinting, Bioassembly, definition

\begin{abstract}
Biofabrication is an evolving research field that has recently received significant attention. In particular, the adoption of Biofabrication concepts within the field of Tissue Engineering and Regenerative Medicine has grown tremendously, and has been accompanied by a growing inconsistency in terminology. This article aims at clarifying the position of Biofabrication as a research field with a special focus on its relation to and application for Tissue Engineering and Regenerative Medicine. Within this context, we propose a refined working definition of Biofabrication, including Bioprinting and Bioassembly as complementary strategies within Biofabrication.
\end{abstract}

\section{Introduction}

Biofabrication is a rapidly growing field of research that continues to develop and is outgrowing its infancy. This is partially due to the expiration of patents covering fused deposition modeling [1], which has rapidly made Additive Manufacturing equipment, commonly known as three-dimensional (3D)-printing, more affordable and widely available. In concert with this lowered cost of equipment has been the transformation of rapid prototyping into rapid manufacturing [2]. Additive Manufacturing methods have also made rapid advances and are now used for the production of high value parts with complex geometries, such as fuel nozzles in gas turbines, and also for low number serial production in medical engineering, as exemplified by the recently FDA approved titanium hip implant components. A similar evolution and expansion of applications has occurred in Biofabrication especially for the fields of Tissue Engineering (TE) and Regenerative Medicine (RM). The journal Biofabrication was founded in 2009 at the beginning of this transition, and these developments have led to the journal recently further clarifying its scope [3]. 
This article aims to survey the history of the term Biofabrication and its different definitions and uses as recorded in the literature to date. More importantly, we believe there is a need to clarify the position of Biofabrication as a research field with a special focus on its relation to and application for TE and RM. Within this context, we propose a refined working definition of Biofabrication, including Bioprinting and Bioassembly as complementary strategies within Biofabrication.

\section{Biofabrication across scientific disciplines}

To our knowledge, the term Biofabrication was first coined in 1994 in relation to the biomineralisation of pearls [4] and later, in 2003, also the deposition of enamel in mammalian teeth [5]. In addition, the US Defence Advanced Research Projects Agency used the definition 'Biofabrication - the use of biological materials and mechanisms for construction' to describe methods used to create high-resolution 3D structures that mimic biological growth mechanisms [6]. In 2004, Biofabrication was used by Payne and co-workers to describe the generation of nanostructured assemblies containing biological materials and/or biocatalysts. In their words, they used a rather broad definition: 'the marriage between biology and microfabrication' [7]. Today, the term Biofabrication is broadly used in the context of fabricating organic/ inorganic hybrid materials or, more generally, fabrication of materials $[8,9]$ by living organisms. Within the TE and RM community, the term Biofabrication emerged with the application of 3D manufacturing strategies incorporating the manipulation and positioning of living cells and/or cell aggregates. This will be discussed in more detail in the subsequent section.

Clearly, the term Biofabrication is currently used by many scientific communities and disciplines to describe different processes and phenomena. There have been a number of attempts to formulate a broad definition of Biofabrication that would embrace its use within these disparate fields. Luo, for example, stated that 'Regardless of the slight emphasis of the definitions, there are several unique features of Biofabrication: first, the building blocks are cells or biologics; second, the fabrication processes are bio-inspired or bio-friendly; and finally, the products are biological systems, models or devices with transformative properties' [10]. This definition does not, however, include biological processes such as biomineralisation, because these are not bioinspired but naturally occurring processes. Hence, since Biofabrication inherently fabricates a product, it could broadly be described as 'a process that results in a defined product with biological function'. This would encompass all the different and novel aspects of Biofabrication, however it would also include several other fields of research and natural processes.

\section{Biofabrication technologies for TE and RM applications}

Here we focus on the technology of Biofabrication that uses cells and materials as building blocks, and which is mainly used for TE and RM applications. Our objective is to summarize, specify and classify the rapidly growing and diverging Biofabrication research activities in the field. The use of printing technologies for 3D positioning of cells was first demonstrated in 1988 by Klebe under the term cytoscribing [11]. Despite the truly pioneering character of this work and possibly because there was a long interval before researchers returned to the concept, this term was not picked up by the subsequent literature. The term 'organ printing', on the other hand, first appeared in 2003 and was defined as 'a rapid prototyping computeraided $3 D$ printing technology, based on using layer-bylayer deposition of cells and/or cell aggregates into a $3 \mathrm{D}$ gel with sequential maturation of the printed construct into perfused and vascularized living tissue or organs' [12]. 'Organ printing' is still frequently used, particularly in the popular literature, however its current usage is often broader than this quite narrow original definition.

The historical evolution of the term Biofabrication, when used in the field of TE and RM, has occurred in parallel with the evolution of the term Bioprinting and possibly this has led to a confusion and possible conflation of the two terms, especially in the popular and journalistic media. Bioprinting was, to the best of our knowledge, first used as a term in the title of the 'Workshop on Bioprinting, Biopatterning and Bioassembly' held at the University of Manchester, UK, in 2004. In a report on this meeting Mironov, Reis and Derby stated: 'For the purpose of the meeting, Bioprinting was defined as: The use of material transfer processes for patterning and assembling biologically relevant materials - molecules, cells, tissues, and biodegradable biomaterials - with a prescribed organization to accomplish one or more biological functions' [13]. The term Bioprinting was subsequently used to specifically describe a process where a mechanical fabrication tool is used to organize or pattern biological entities in two- or three-dimensions to build an artificial construct [14]. In 2010 Guillemot et al defined Bioprinting as 'the use of computer-aided transfer processes for patterning and assembling living and non-living materials with a prescribed 2D or 3D organization in order to produce bioengineered structures serving in regenerative medicine, pharmacokinetic and basic cell biology studies' [15]. It is thus clearly related to the parallel development of Additive Manufacturing that was then emerging as an engineering fabrication tool. Consequently, Biofabrication was first defined by Mironov et al in the inaugural issue of the journal Biofabrication in 2009 as 'the production of complex living and non-living biological products from raw materials such as living cells, molecules, extracellular matrices, and biomaterials' [16]. 


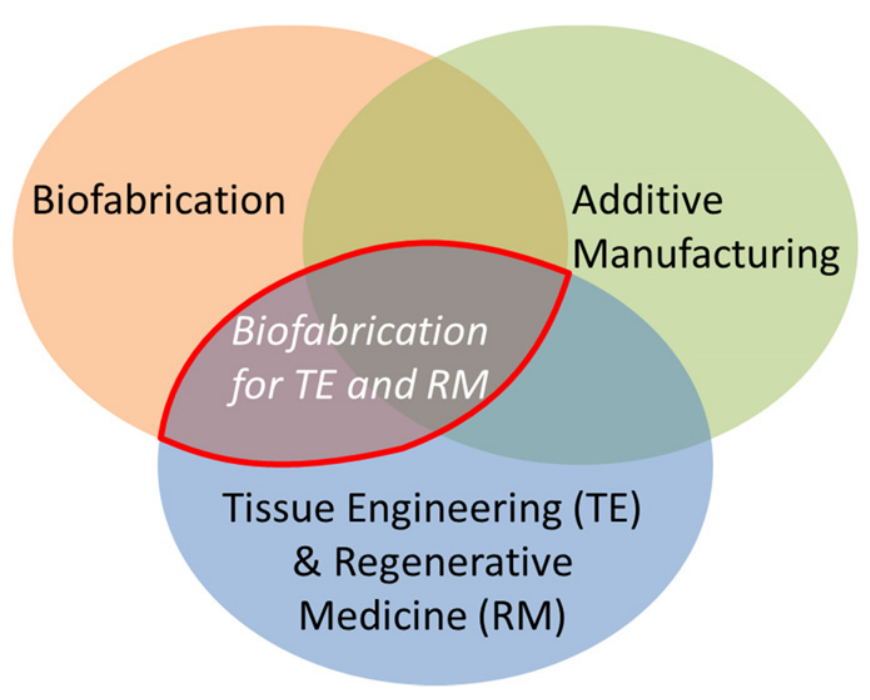

Figure 1. Schematic venn diagram illustrating the interrelation between Biofabrication, Additive Manufacturing, and the related fields of Tissue Engineering (TE) and Regenerative Medicine (RM). Size of the areas and the overlaps does not represent the scale of the research fields.

It is evident that the terms Bioprinting and Biofabrication are closely related, and since their respective existing definitions overlap, it is extremely difficult to effectively differentiate them. As a consequence, they are often used inconsistently or interchangeably, which underscores the need for clarification. As recently pointed out by Hutmacher and colleagues $[17,18]$, it would be beneficial for a new ASTM/ISO norm to be developed, or for a new sub-norm to be defined under ASTM F2792 in order to unambiguously define the terms Biofabrication and Bioprinting. Beyond this more technical approach, and as already suggested by Boland and Mironov [19], we believe that determining the positioning of Biofabrication as a research field and its relationship with TE and RM will help in clarifying these definitions.

\section{Biofabrication and its relation to $\mathrm{TE}$ and RM}

TE was defined in 1993 as 'an interdisciplinary field that applies the principles of engineering and life sciences towards the development of biological substitutes that restore, maintain, or improve biological tissue function or a whole organ' [20]. The field of TE has grown and expanded since 1993, and its definition has been extended accordingly. In 2007, for example, 12 federal agencies in the US proposed a combined definition of Tissue Science and TE as: 'The use of physical, chemical, biological, and engineering processes to control and direct the aggregate behavior of cells' [22]. More importantly, the field of RM has been defined as 'the application of tissue science, tissue engineering, and related biological and engineering principles that restore the structure and function of damaged tissues and organs' [23]. This includes not only in vivo but also in vitro generation of functional tissue analogues for various purposes such as drug testing, disease models, including cell/tissue/ organ-on-a-chip approaches. Within TE and RM, Biofabrication provides a core and vital technology for these emerging applications that is not restricted simply to Additive Manufacturing approaches (figure 1).

With the classical TE approach, cells are seeded onto a prefabricated scaffold, typically in conjunction with the delivery of bioactive factors that ensure maintenance of cellular phenotype and appropriate extracellular matrix formation. This is achieved through in vitro maturation followed by subsequent implantation, with the aim to functionally regenerate tissue (figure 2). An alternative concept envisions the development of in vitro 3D tissue models, that exhibit functional features of native tissues, for application in an in vitro testing or screening system. A more recent approach, in line with the strategy of RM, is so-called in situ TE or in situ tissue regeneration, which omits in vitro cell culture and/or in vitro tissue maturation steps. This approach aims instead to design materials and/or exploit the use of chemokines to recruit resident (stem-) cells to the scaffold and modulate the local immune response, inducing regenerative mechanisms in situ [21]. It is within this context that Additive Manufacturing has been, and still is, used to generate biomedical implants and scaffolds for seeding with cells in a classical TE approach.

From a research strategy perspective, Biofabrication within TE and RM aims at exploiting automated processes, for the most part Additive Manufacturing techniques, to generate cell-biomaterial constructs that, through their internal and external spatial arrangement may mature into functional tissue equivalents. Accordingly, these strategies typically target the development of scaffolds or composite 


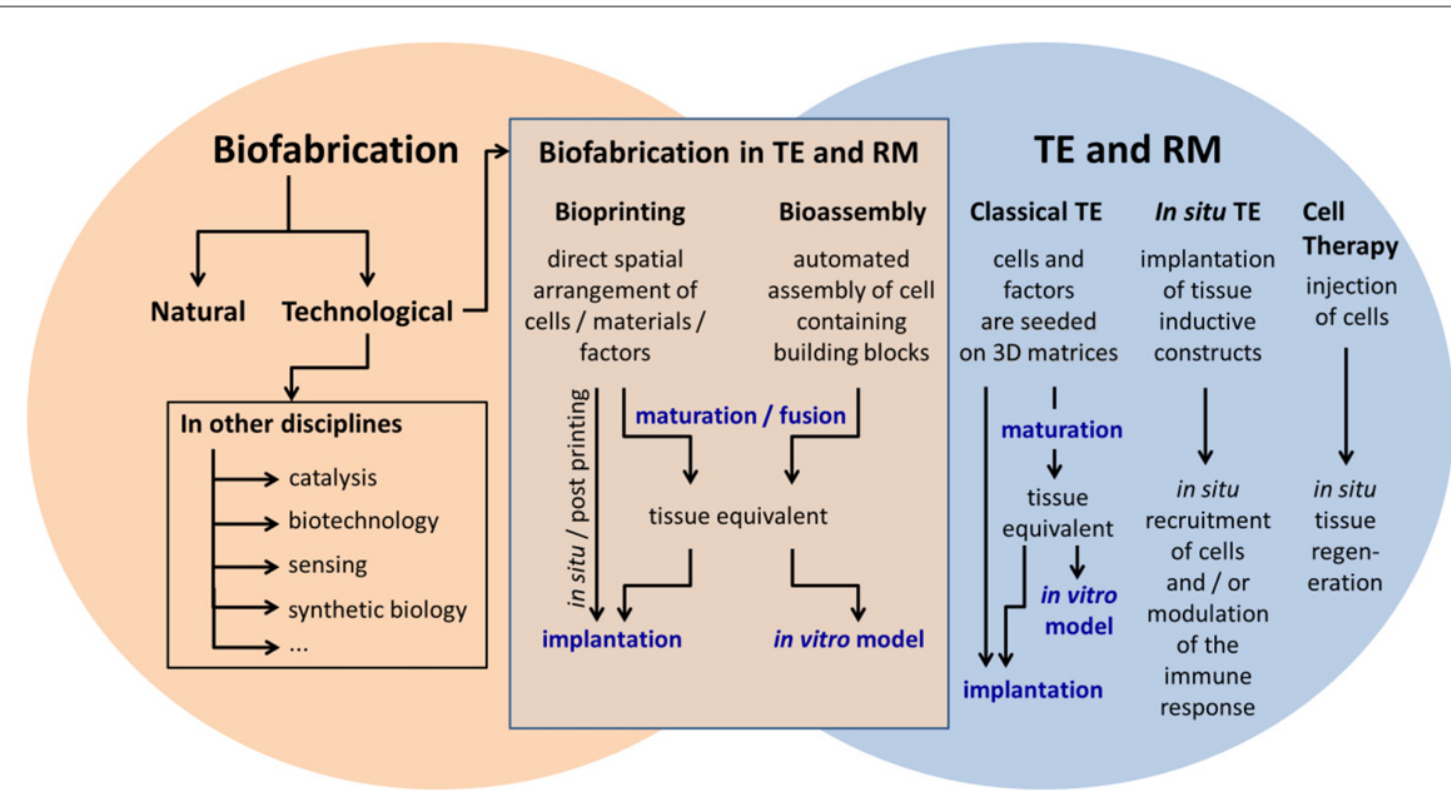

Figure 2. The term Biofabrication is used to describe natural processes such as biomineralization and technological processes in various disciplines such as catalysis, biotechnology, sensing, synthetic biology, and especially TE and RM. For application within TE and RM, Biofabrication can generally be divided into two distinct approaches, Bioprinting and Bioassembly.

constructs which exhibit tissue mimetic hierarchical features. Alternatively, these constructs are produced with a structural organization that induces or modulates the host response after implantation through paracrine effects. When living single cells, bioactive molecules, biomaterials, or cell-aggregates small enough to be printed are used for fabrication, the mentioned constructs can be achieved by Bioprinting as defined earlier [15], which is one of the two main strategies of Biofabrication. We note that Additive Manufacturing of 3D scaffolds followed by seeding with cells complies with this strategy when the subsequent maturation process yields a structural biologically functional construct. This can for example be achieved by the scaffold instructing or inducing the cells to develop into a tissue mimetic or tissue analogue structure, for example, through distinctive cell interaction, hierarchical induction of differentiation or functional evolution of the manufactured scaffold.

An alternative strategy for fabricating such constructs is to work with larger pre-formed multicellular fabrication units in the form of cell aggregates, cell fibers, cell sheets or more complex structures, such as organoids or microtissues, comprising cells and their extracellular matrix. These more complex building blocks are formed through cell-driven self-organization in $3 \mathrm{D}$ or lower dimension culture, i.e. through a bottom-up approach, often through the use of enabling technologies, such as microfabricated molds or microfluidics, followed by tissue fusion and maturation. Another possible form of these building blocks are hybrid cell-material constructs, also referred to as hybrid tissues, for example cell loaded microgels and microcarrier beads [24-26]. A number of automated assembly techniques are available for
Biofabrication using these building blocks, which can be subsumed under the term Bioassembly. Depending on the size, shape and geometry of the cell-containing units, Bioassembly encompasses a number of methods including Additive Manufacturing techniques, but also others, such as textile manufacturing routes like weaving, winding and knitting when cell fibers are used as building blocks [27]. Also, classical Additive Manufacturing of biomaterials can be used to generate templates for Bioassembly. Thus, Bioassembly as a second major strategy of Biofabrication can be defined as 'the fabrication of hierarchical constructs with a prescribed $2 \mathrm{D}$ or $3 \mathrm{D}$ organization through automated assembly of pre-formed cell-containing fabrication units generated via cell-driven self-organization or through preparation of hybrid cell-material building blocks, typically by applying enabling technologies, including microfabricated molds or microfluidics'.

Thus, we consider the general area of Biofabrication within the context of TE and RM should be distinguished from its use in the area of natural processes, such as biomineralisation and be confined to manufacturing processes as discussed above. Within this technology space, we propose that there are two distinct methodologies that can be distinguished by the length scale of the minimum fabrication unit (pixel or voxel). These are 'Bioprinting' according to the definition by Guillemot et al [15] and 'Bioassembly'. For Bioprinting, the minimum fabrication unit is down to molecular level. In the case of Bioassembly, the minimum fabrication units are pre-formed cell containing building blocks with sizes large enough so that automated assembly can technologically be achieved. Figure 2 shows the interrelation between these terms in a schematic diagram. We note that the aim of 
Biofabrication is to generate a construct with biological function. Hence, in most cases neither Bioprinting nor Bioassembly fully describe the complete Biofabrication process, which is usually dependent on a maturation phase for the constructed pre-tissue assembly to allow it to develop a continuous and coherent functional structure. This maturation process may occur either in vitro with a culture phasetypically adopting the use of bioreactor technologyor conceivably in vivo after transplantation.

Taking into account these dynamic and evolving research activities and developments of different technological aspects, we suggest the following revised working definition of Biofabrication for TE and RM as 'the automated generation of biologically functional products with structural organization from living cells, bioactive molecules, biomaterials, cell aggregates such as micro-tissues, or hybrid cell-material constructs, through Bioprinting or Bioassembly and subsequent tissue maturation processes.'

\section{References}

[1] http://creax.com/2014/07/technology-mapping-influenceip-3d-printing-evolution/

[2] Berman B 2012 3D Printing: the new industrial revolution Bus. Horizons 55 155-162

[3] http://iopscience.iop.org/1758-5090/page/Scope

[4] Fritz M, Belcher A M, Radmacher M, Walters D A, Hansma P K, Stucky G D, Morse D E and Mann S 1994 Flat pearls from biofabrication of organized composites on inorganic substrates Nature 371 49-51

[5] Fong H, White S N, Paine M L, Luo W, Snead M L and Sarikaya M 2003 Enamel structure properties controlled by engineered proteins in transgenic mice J. Bone Miner. Res. 18 2052-9

[6] Liu Y, Kim E, Ghodssi R, Rubloff G W, Culver J N, Bentley W E and Payne G F 2010 Biofabrication to build the biology-device interface Biofabrication 2022002

[7] Wu L Q and Payne G F 2004 Biofabrication: using biological materials and biocatalysts to construct nanostructured assemblies Trends Biotechnol. 22 593-9

[8] Zaremba C M, Belcher A M, Fritz M, LiY L, Mann S, Hansma P K, Morse D E, Speck J S and Stucky G D 1996 Critical transitions in the biofabrication of abalone shells and flat pearls Chem. Mater. 8679-90

[9] Schroder H C, Wang X H, Tremel W, Ushijima H and Muller W E G 2008 Biofabrication of biosilica-glass by living organisms Nat. Prod. Rep. 25 455-74

[10] Luo X 2012 Biofabrication in microfluidics: a converging fabrication paradigm to exploit biology in microsystems J. Bioeng. Biomed. Sci. $21000 \mathrm{e} 104$
[11] Klebe R J 1988 Cytoscribing: a method for micropositioning cells and the construction of two- and three-dimensional synthetic tissues Exp. Cell. Res. 179 362-73

[12] Mironov V, Boland T, Trusk T, Forgacs G and Markwald R R 2003 Organ printing: computer-aided jet-based 3D tissue engineering Trends Biotechnol. 21 157-61

[13] Mironov V, Reis N and Derby B 2006 Bioprinting: a beginning Tissue Eng. 12 631-4

[14] Derby B 2008 Bioprinting: inkjet printing proteins and hybrid cell-containing materials and structures J. Mater. Chem. 18 5717-21

[15] Guillemot F, Mironov V and Nakamura M 2010 Bioprinting is coming of age: report from the International Conference on Bioprinting and Biofabrication in Bordeaux (3B'09) Biofabrication 201020

[16] Mironov V, Trusk T, Kasyanov V, Little S, Swaja R and Markwald R 2009 Biofabrication: a 21st century manufacturing paradigm Biofabrication 1022001

[17] Hutmacher D W 2015 Bioprinting, biofabrication, biomanufacturing? The need for definitions and norms in additive manufacturing in the biomedical sciences MRS Bull. 40113

[18] Chhaya M P, Poh P S P, Balmayor E R, van Griensven M, Schantz J-T and Hutmacher D W 2015 Additive manufacturing in biomedical sciences and the need for definitions and norms Expert Rev. Med. Devices 12 537-43

[19] Boland T and Mironov V 2014 How to Define Biofabrication? Review of the Book Biofabrication: Micro- and NanoFabrication, Printing, Patterning, and Assemblies 3D Print. Additive Manuf. vol 1, ed G Forgacs and W Sun (New York: William Andrew) pp 52-4

[20] Langer R and Vacanti J P 1993 Tissue engineering Science 260 $920-6$

[21] Ko I K, Lee S J, Atala A and Yoo J J 2013 In situ tissue regeneration through host stem cell recruitment Exp. Mol. Med. 45 e 57

[22] US National Science and Technology Council 2007 Advancing tissue science \& engineering: a multi-agency strategic plan available at: (https:/ / whitehouse.gov/sites/default/files/ microsites/ostp/advancing_tissue_science-engineering.pdf)

[23] US Department of Health and Human Services 2006 A new vision-a future for regenerative medicine, available at: (http://medicine.osu.edu/regenerativemedicine/ documents/2020vision.pdf)

[24] Nichol JW and Khademhosseini A 2009 Modular tissue engineering: engineering biological tissues from the bottom up Soft Matter 5 1312-

[25] Elbert D L 2011 Bottom-up tissue engineering Curr. Opin. Biotechnol. 22 674-80

[26] Guven S, Chen P, Inci F, Tasoglu S, Erkmen B and Demirci U 2015 Multiscale assembly for tissue engineering and regenerative medicine Trends Biotechnol. 33 269-79

[27] Onoe H et al 2013 Metre-long cell-laden microfibres exhibit tissue morphologies and functions Nat. Mater. 12 $584-90$ 